\title{
Aerodynamics of the Supersonic Guide Surface Parachute
}

\author{
HeLmut G. Heinrich* \\ University of Minnesota, Minneapolis, Minn.
}

\begin{abstract}
Shock waves, pressure distribution, and mass flow, which influence the performance of a parachute in supersonic flow, are discussed, and several advantageous conditions are postulated. Respective experiments were made with models consisting of modified 4-in.--diam guide surface canopies, combined with a cone located ahead of the canopy. Textile, as well as rigid models, functioned satisfactorily up to Mach numbers of 4.5. A 4-ft supersonic guide surface parachute, its design based on the model tests, worked satisfactorily in a wind tunnel at velocities up to Mach 2.8. It failed after 90-min testing time because of fatigue.
\end{abstract}

\section{Introduction}

CONVENTIONAL solid cloth and ribbon parachutes, 1 which funetion satisfactorily at subsonic speeds, display aerodynamic and structural instability in supersonic flow, relatively low and uncertain drag coefficients, and, in general, they are destroyed by fatigue shortly after their deployment. ${ }^{1-3}$

The reason for this erratic behavior is an unsteady system of shock waves and wakes as illustrated in Fig. 1. Unsteady shocks are typical for cavities that allow none or an insufficient mass flow through the cavity. This is illustrated in Figs. 2 and 3, which show the flow about a nonporous hemisphere and a cylindrical tube in which mass flow has been regulated from zero to full accommodation of the respective stream tube. One observes that on the cylinder a steady normal shock develops when the proper mass flow is established. The flow pictures are double exposures at Mach 3.0 with the spark-schlieren technique in intervals of approximately 2 sec. $^{4}$

In Fig. 1, one notices that the oscillating shocks occasionally attach themselves to the parachute suspension lines. The suspension lines also may trigger and enhance unsteadiness of the flow pattern. ${ }^{2}$ The role of the suspension-line boundarylayer interferences with the canopy bow shock will be discussed later in more detail.

The experiments described previously explain why the modified ribbon parachutes, so-called Equiflo and Hemisflo parachutes, which allow a considerable mass flow through the canopy, have functioned satisfactorily up to Mach numbers of 1.8. $\mathrm{A}$ further development in this line is the Hyperflo parachute, which has functioned satisfactorily up to Mach numbers in the order of 4.0. Hyperflo parachutes consist of a nonporous front portion, shaped somewhat like a guide surface, and a very porous flat roof. ${ }^{6}$

The Hyperflo parachute is certainly a significant development, but it also appeared desirable to study the possibilities of designing a supersonic parachute on different and easy to understand principles. Before proceeding in this attempt, it is advantageous to review the consequences of the unsteady flow upon the functioning of a flexible parachute canopy.

An unsteady flow pattern causes unsymmetrical air spillage over the rim of the canopy (Fig. 2), and a continuous shift of the center of pressure, which leads to violent oscillations of the canopy. The spillage is accompanied by a swallowing and expulsion of the frontal shock. This causes a fluctuating and unsymmetrical pressure distribution and promotes erratic deformations of the flexible canopy with new unsymmetrical shock waves, spillage, etc. In view of this experience, it was decided to devise a new supersonic parachute that would avoid unsteady flow patterns and in which frontal shock

Received January 29, 1965; revision received October 7, 1965. This project was sponsored under Air Furce Contract AF 33(615)2554. Associate Fellow Member AIAA

* Professor of Aero-Space Engineering. waves should not originate at or intersect with any part of the flexible canopy. Therefore, it appeared necessary to depart from conventional forms of subsonic or transonic parachutes, but to start from scratch.

Furthermore, it was decided to perform the bulk of the investigations with relatively small and inexpensive models in wind tunnels and other research facilities and later to translate the findings of the model tests into terms for suitable fullsize parachutes. The course of this development and its findings are presented in the following chapters.

\section{Postulated Principles}

Conventional subsonic parachutes allow a small mass flow through the porous canopy material or through the open spaces of ribbon and ringslot parachutes. Thus, in principle, these parachutes convert practically the entire kinetic energy of the air which enters into the canopy into pressure in one step. In supersonic flow, such a strong energy conversion easily may lead to relatively large, unsymmetrical canopy deformation, which causes unsymmetrical and unsteady flow patterns. Therefore, it was postulated that the projected supersonic parachutes should act somewhat like a supersonicsubsonic diffusor, and its useful drag would be developed merely from a partial energy conversion of the captured air. Furthermore, the new decelerator should accomplish even the partial conversion in several controlled steps.
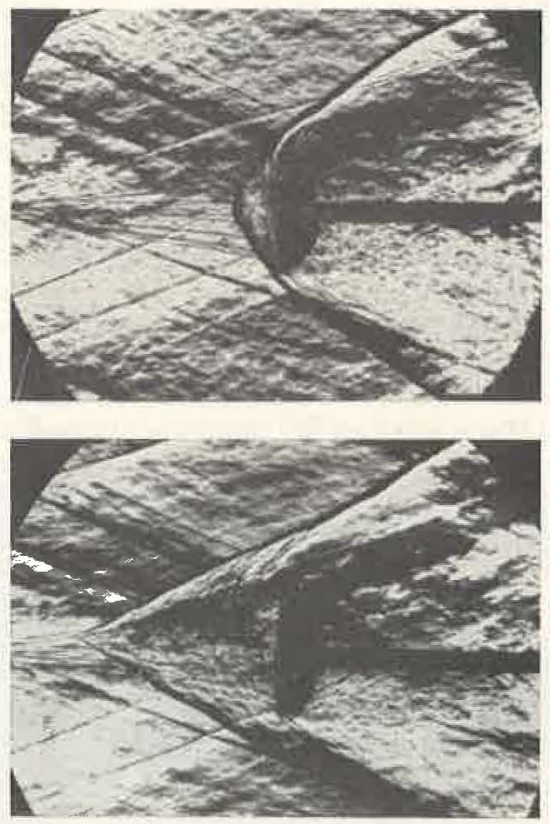

Fig. 1 Schlieren pictures of a rigid ribbon parachute model at Mach number 3 . 

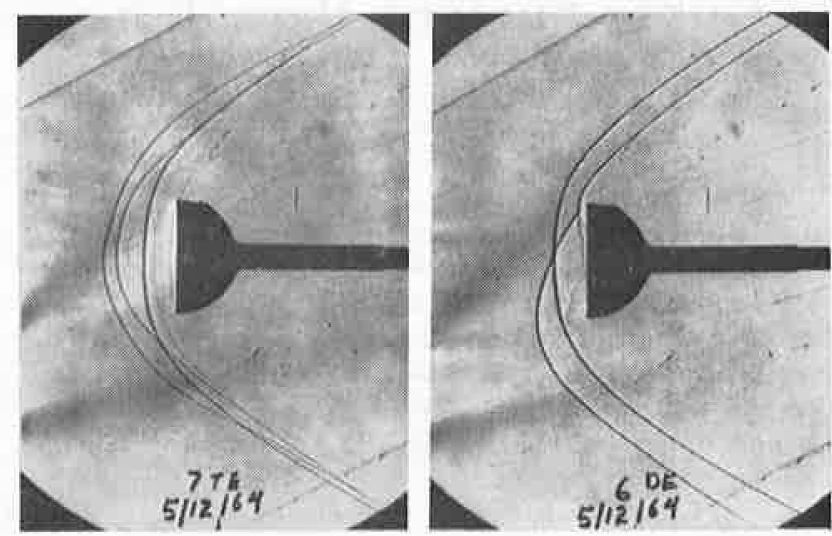

Fig. 2 Unsteady shock-wave pattern of a hollow hemisphere at Mach number 3.

Such a decelerator, parachute, or flow converter has been conceived as a combination of a pointed or blunted cone and a more or less hemispherical canopy, as schematically illustrated in Fig. 4. In this arrangement, the pressure conversion is accomplished first through the shock on the cone and secondly ahead of or within the canopy. The cone, with its apex placed ahead of the canopy, also guides the air so that its deflection inside the canopy and near the rim develops an outwardly directed force that provides a certain canopy inflation tendency.

The tip of the cone with its attached shock wave fixes the location of the stagnation point and, to a certain extent, the center of pressure of the system. This is advantageous in view of aerodynamic stability and heating.

As further requirements, it is postulated that the conical shock should never hit the inlet rim of the canopy. This condition prevents a hitting and missing shock wave at the rim which could easily occur because of unavoidable small variations in the geometry of the cone-canopy combination. A shock that hits and misses various parts of the rim would tend to cause unsymmetries of the canopy inlet. This deformation, in turn, would promote unsymmetrical and unsteady How patterns, new canopy deformation, oscillation, spillage, etc.

The canopy outlet should be large enough to accommodate the mass flow of the stream tube whose surface intersects with the canopy inlet rim. Compared to the freestream, the discharged air would have a higher density and less velocity than the entering air. Thus, this decelerator would not utilize the entire flow energy; however, spillage and its undesirable consequences would be avoided.

The scheme of the projected supersonic parachute (Fig. 4) shows a cone with a streamlined back and a shell-like canopy. Both are suitably arranged to each other. Besides the conditions postulated heretofore, the cross-sectional area between the cone and the canopy should be such that the flow inside the canopy is transonic. Furthermore, the cone angle $\theta$, the freestream Mach number $M_{1}$, and the standoff distance $H$ are the parameters that control the fulfillment of the postula-
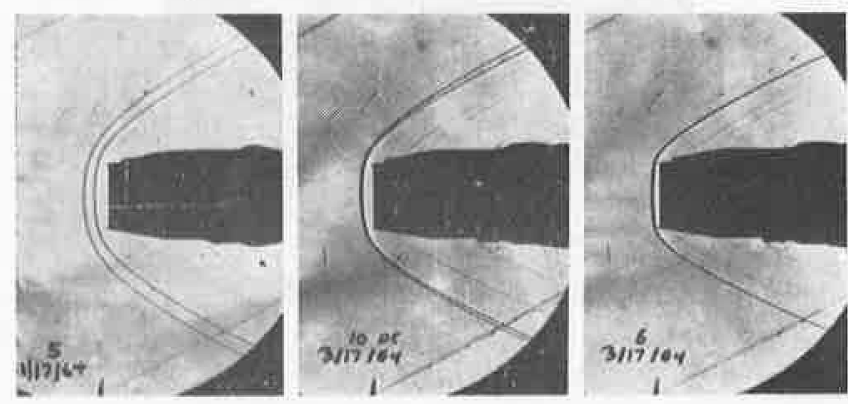

Fig. 3 Shock-wave pattern at Mach number 3 of a hollow cylinder with varying mass flow through the cylinder.

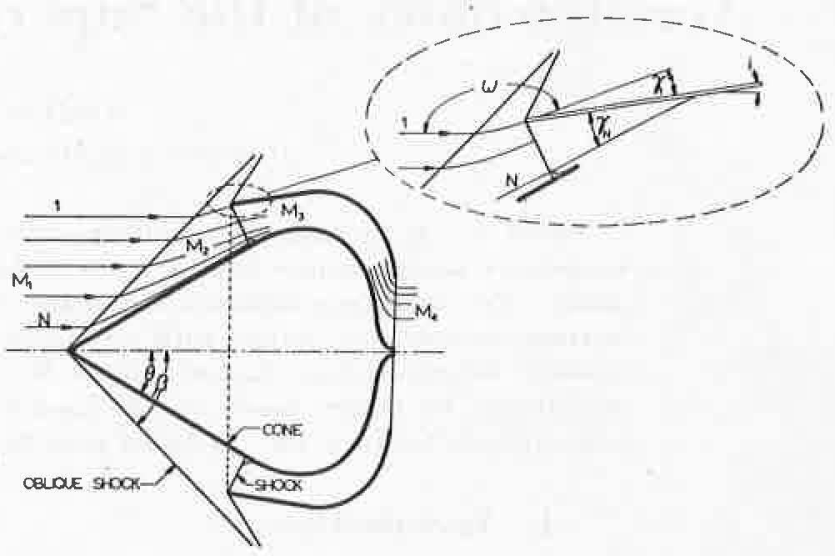

Fig. 4 Scheme of supersonic guide surface parachute.

tions. Several of these can be determined from the basic theory of supersonic flow, whereas others must be found experimentally.

For example, the angle of internal impact $\gamma=\pi-(\omega+\iota)$, in which $\omega$ is the deflection angle of the streamline and $\iota$ the angle of incidence of the guide surface, is a design characteristic that can be calculated from the theory of supersonic flow and from the basic parameters. For example, for a Mach number of 3 , a cone angle $\theta=34^{\circ}$, and angle of incidence $\iota=$ $10^{\circ}$, the impact angle near the rim is $\gamma=2.5^{\circ}$. It increases to $24^{\circ}$ at farther distances. Conditions like this must first be assumed, and experiments are needed to check their suitability.

Figure 4 shows a rather large cone, which, when rigid, would eliminate one of the main advantages of a parachute, namely, its small storage volume. To avoid the large rigid cone, it has been attempted to replace the rear section of the cone by a diverging wake. In supersonic flow, a diverging wake can be achieved when the static pressure in the wake is held at a certain level. In case of the visualized supersonic parachute, a positive pressure gradient can be derived from the flow about the curved inside contour of the canopy. This condition requires, then, certain experiments in order to establish the optimum standoff distance $H$.

In view of these considerations the rigid cone, as shown in Fig. 4, has been replaced in Fig. 5 by a diverging wake. Also, the canopy now may be considered to be flexible, and the controlling parameters are identified.

Figures 4 and 5 show a sharp-edge abrupt canopy outlet. It must be realized that in this area the passing flow probably will be accelerated, in all supersonic operations, from subsonic to sonic speed. In the vicinity of the indicated sharp edge, very high-pressure gradients and a strong vortex development in the wake must be expected. The downstream

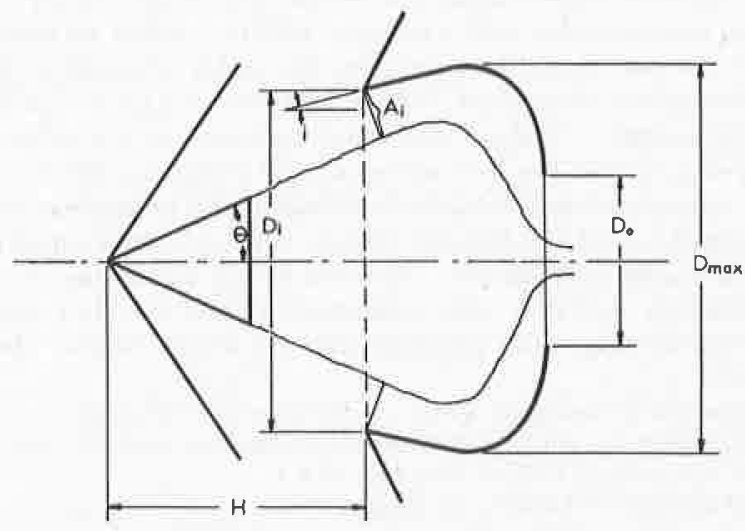

Fig. 5 Parameters of the supersonic guide surface parachute. 
vortices may affect the formation of the wake cone adversely and jeopardize the functioning of the system. Indeed, this has happened occasionally and later a somewhat conventional subsonic nozzle was added.

The projected supersonic parachute derives, to a certain extent, its static stability from its conical frontal surface. In this respect, it has a strong similarity with the known subsonic guide surface parachutes and will therefore, in the following sections, be called supersonic guide surface parachute.

\section{Experimental Approach}

In view of the numerous unconventional ideas for the development of a new supersonic parachute, a combined analytical and experimental effort was pursued. In the analytical approach, one may assume the shape of the diverging wake and the flexible canopy as presented in Figs. 4 and 5, select the cone angle, and determine the shock waves and their pressure rises. The area between wake cone and rim is then a function of Mach number and the respective mass flow. The standoff distance $H$ must be chosen in view of Mach number, cone angle, mass flow conditions, and from the requirement that the shock waves originating at the cone shall not interesect with the rim of the canopy. On the other hand, the formation of a diverging wake, which must aerodynamically act like a solid body, is a function of Reynolds number and, as such, must be investigated experimentally.

In the experimental approach, models built in accordance with the given guide lines will be tested to check the validity of the more theoretical assumptions and to make necessary adjustments. The model experiments also will serve to study some design features of flexible eanopies which will be useful for the construction of full-size parachutes.

Under these principles a test program was established in which first two-dimensional models were studied in a water analogy facility, then rigid and flexible models in a supersonic wind tunnel, and finally a larger model of full-size parachute was tested in a sufficiently large wind tunnel.

\section{A. Water Analogy Studies}

Surface-wave analogy experiments offer the possibility of studying basic flow conditions in a most convenient and inexpensive manner. The studies are, of course, limited to twodimensional conditions, but, when properly interpreted, they provide valuable information for the functioning of threedimensional systems. ${ }^{7}$ Therefore, the projected supersonic

\section{TWO-DIMENSIONAL}

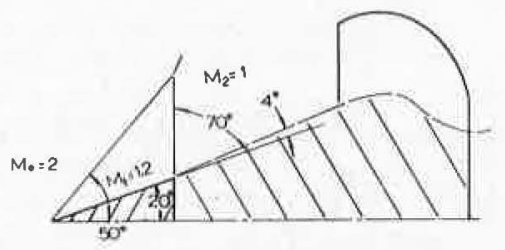

THREE - DIMENSIONAL

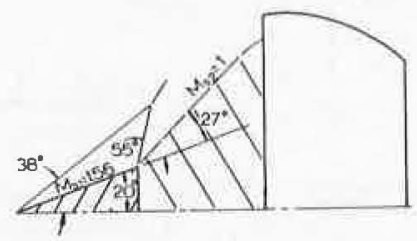

Fig. 6 Calculated flow pattern for two- and three-dimensional models of the supersonic guide surface parachute.

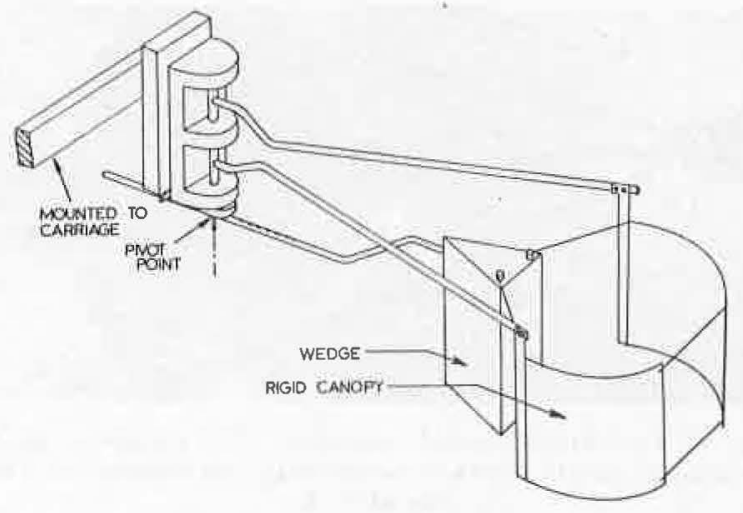

Fig. 7 Surface wave analogy model of the supersonic guide surface parachute.

parachute was considered to be a two-dimensional and threedimensional object, and certain calculations were performed.

These calculations are based on the following assumptions. In supersonic flow an oblique shock is generated on the wedge and a conical shock on the cone. The solid cone is effectively extended by a divergent wake, which acts like a solid body and causes, in conjunction with the internal surface of the canopy, a second shock that again reduces the velocity and increases the pressure. If one assumes that the flow within the canopy is near sonic and that the pressure in the wake is approximately equal to the pressure of the sonic flow, then the wake must diverge to such a degree that the pressure in the flow adjacent to the wake and in the region between cone base and canopy inlet is equal to the pressure in the wake. This condition determines the schematic flow pattern for the twodimensional and three-dimensional models shown in Fig. 6. One observes that for Mach 2 and for the chosen geometry in both cases the wake divergence angle must be a little larger than the wedge or cone angles.

For the water analogy studies semiflexible, two-dimensional models were built as shown in Fig. 7. The models were fastened to the carriage of the shallow water tow tank and various combinations of the design parameters (Fig. 5) were investigated.

Figures 8 and 9 show a stable and an unstable configuration. Under stable configuration, an arrangement is understood in which the shock wave pattern is steady and the model has a recognizable aerodynamic stability. Both figures show the oblique shock, a second shock wave at the base of the cone, a number of shocks perpendicular to the wake contour, and a final normal shock across the effective canopy inlet area. Furthermore, a curved shock located at a considerable distance from the canopy encompasses the entire canopy.

In view of stable and unstable configurations, one notices that the dye behind the solid wedge shows either a symmetrical and steady wedge-like wake or, in the case of the unstable configuration, an unsymmetrically located and unsteady

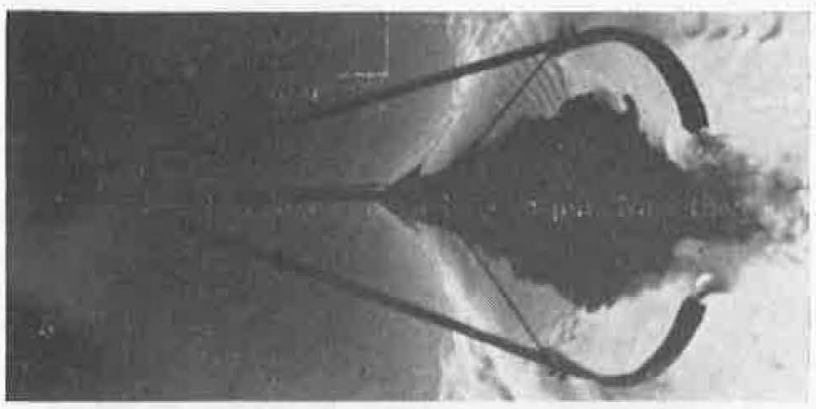

Fig. 8 Two-dimensional stable configuration of the supersonic guide surface parachute at simulated Mach number 2. 


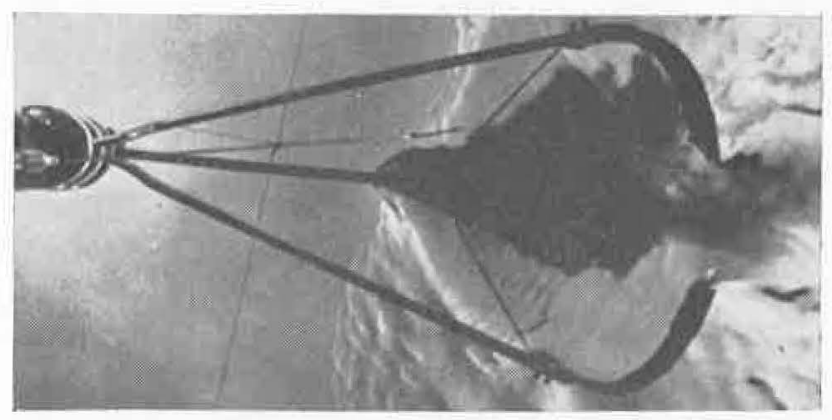

Fig. 9 Two-dimensional unstable configuration of the supersonic guide surface parachute at simulated Mach number 3.

wake. Also, the oblique shock at the wedge and the practieally normal shock near the inlet area of the canopy are either symmetrical or unsymmetrical for the stable and unstable configurations, respectively. The principal characteristies of stable and unstable configurations are summarized in Figs. 10a and $10 \mathrm{~b}$.

For the tests, a large number of design parameter combinations is, of course, possible. However, because of practical requirements concerning the location of the oblique shock, the necessity of developing a stable and diverging wake, and a continuous flow through the parachute without spillage, the practical combinations are limited. Therefore, merely the standoff distance was changed which effectively caused a variation of the wake area and the related effective inlet area $A i$ in Fig. 5. Under otherwise identical test conditions, the ratio of the effective inlet to outlet area vs standoff distance has been used as design criteria, and Fig. 11 shows the results of the experiments as a function of these parameters. It can be seen that over a certain range of standoff distance stable configurations were obtained with area ratios in the order of unity. This is in agreement with the assumption that the flow velocity at the canopy inlet and outlet is essentially the same. The experiments showed further that the configurations became unstable when the oblique shock from. the wedge intersected with the canopy rim, standoff distance was too short, or when the wake became unstable because the standoff distance was too large.

In summary, then, it can be concluded that in two-dimensional flow a number of configurations functioned satis-

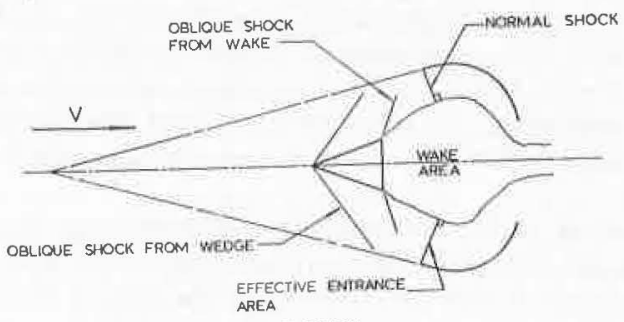

A) StABLle CONFIgURATION

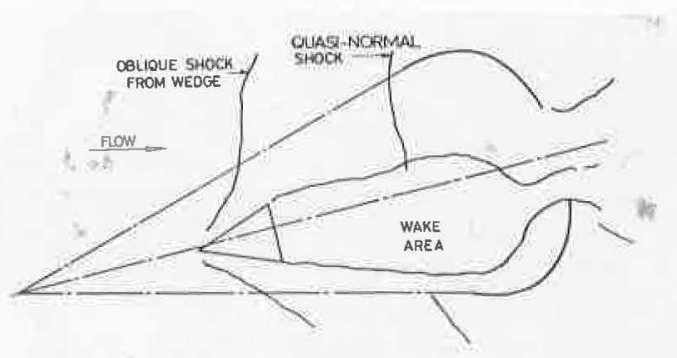

B) UNSTABLE CONFIGURATION

Fig. 10 Characteristics of a stable and an unstable configuration of two-dimensional models of the supersonic guide surface parachute. factorily and that the analysis of the test results confirmed the postulated concept.

\section{B. Wind-Tunnel Experiments}

Encouraged by the surface wave analogy studies, stingmounted rigid models with 4 -in. diam, representing the supersonic guide surface parachute, were tested in a supersonic wind tunnel. The model dimensions were in accordanee with Fig. 6. However, arrangements were made to vary the inlet-to-outlet area ratio, as well as the standoff distance. As expected, the varions models produced stable and unstable configurations. In general, the models were stable when their geometry was in accordance with those configurations that were stable in the water analogy tests. A typical schlieren picture of one of these stable configurations is shown in Fig. 12. Several of such schlieren pictures have been analyzed and a characteristic result is shown in Fig. 13. In comparing Fig. 13 with the calculated shock-wave pattern of the threedimensional model shown in Fig. 6, one notices a surprisingly good agreement between recording and calculation.

In Ref. 2 it was stated that the interaction of the boundary layer of the suspension lines with the bow shock of the main canopy may cause unsteady flow pattern. Because of this possibility, a rigid supersonic guide surface model was equipped with nylon suspension lines with a diameter of about $1 \%$ of the projected canopy diameter. No interference or unsteadiness at Mach numbers of 2 and 3 was recorded.s However, in further tests it was observed that, in models with unsteady flow pattern because of standoff distances or faulty area ratios, the oscillating shock waves attached themselves momentarily to the suspension lines. Therefore, it may be concluded that, on the supersonic guide surface parachute the suspension lines do not interfere if the shock waves are arranged in aecordance with the concept and spillage over the inlet is avoided.

After these exploratory tests, flexible models were studied in order to observe their opening tendency, structural rigidity, and other characteristics. The flexibility introduces a number of difficulties, since the canopy must attain its proper semirigid shape from its pressure distribution, which, in turn, is determined by the flow pattern. Also, the flow pattern must be such that the parachute is aerodynamically stable.

In view of these eonditions, the pressure distribution of a stable and steady configuration was established and a mumber of interesting details were found. First, the relatively thick suspension lines lower the internal pressure near the entrance area. Therefore, the suspension lines are detrimental to the rigidity of the pressure-supported parachute canopy. However, even with suspension lines, the internal pressure is, over the entire region, higher than the external pressure, and a flexible eanopy should be properly rigidized.

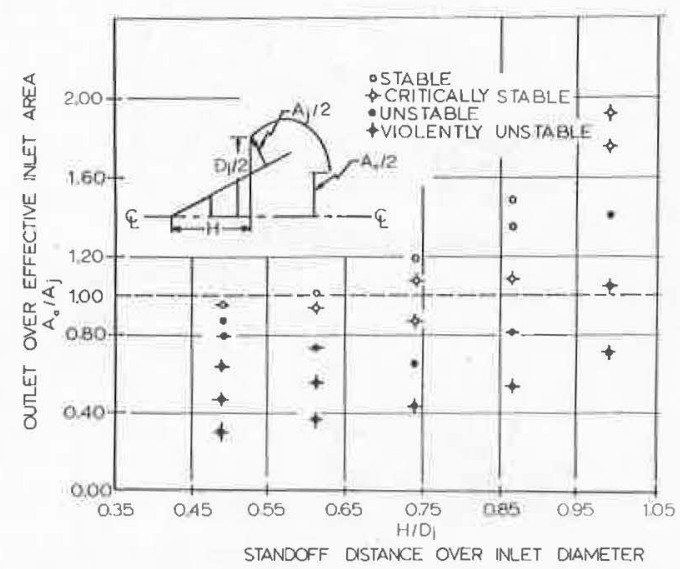

Fig. 11 Evaluation of surface wave analogy experiments at simulated Mach number 2. 


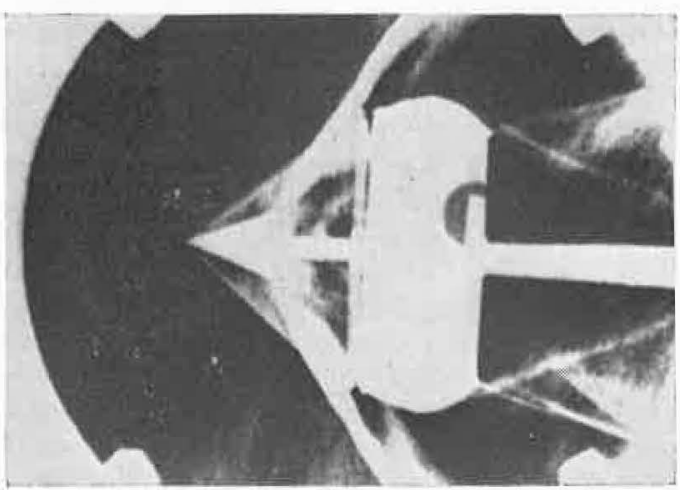

Fig. 12 Shock-wave pattern of a stable configuration of a rigid supersonic guide surface parachute model at Mach number 2.

The measurements also show, that the pressure on the base of the cone is about equal to the pressure near the inlet area of the canopy. This is in good agreement with the results of the two-dimensional water analogy study and with the evaluation of the schlieren pictures of stable wind-tunnel models. More details about the pressure distribution are given in Ref. 8.

Corresponding to the rigid models, flexible models with 4in. diam were built which had a rigid cone, a Nylon cloth eanopy, and a suitable arrangement of $\mathrm{N} y$ lon suspension lines.

The initial wind-tunnel experiments with flexible models were very discouraging. In spite of motion pictures with. 2000 frames/sec, the parachutes were destroyed before one could determine if insufficient strength or serodynamic reasons had eaused the malfunctions. However, based on many small indications, the strength of the models was improved, and they lasted at least long enough to recognize aerodynamic details. These successful tests showed that the flexible models had the same aerodynamic characteristics as the rigid ones. However, occasionally, failures occurred which appeared to be caused by aerodynamic reasons. It was theorized that the sharp edge at the outlet with its strong pressure gradient did promote the formation of powerful vortices that could cause dislocations and oscillations of the internal diverging wake. This, of course, would interfere with the mass flow and could cause spillage at the inlet. In support of this speculation, the flowfield surrounding the canopy contour was investigated on two-dimensional models, and Figs. $14 \mathrm{a}$ and $14 \mathrm{~b}$ illustrate the pressure field of the eanopy with and without subsonic outlet nozzle. One notices that the outlet nozzle reduces the pressure gradients significantly, which measure should, in turn, decrease the strength of the wake vortices. It is interesting to see that the isobars in both figures outline a large field of constant pressure which is essentially the ares of the diverging wake. The location. of shock waves also is indicated.

In view of the established pressure fields, all flexible models were equipped with outlet nozales, and the results were very good. In the Mach number range from 0.9 to 4.5 , the models showed aerodynamic stability and steadiness, structural rigidity, as well as durability. Many models were tested several times. The tests were made in freestream and in the wake of a forebody located 8-body diam ahead of the parachute rim. The forebody diameter was $45 \%$ of the

Fig. 13 Schematic shock-wave pattern obtained from schlieren pictures of a rigid supersonic guide surface parachute model at

Mach number 2.

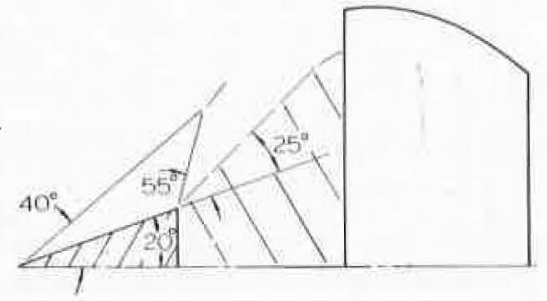

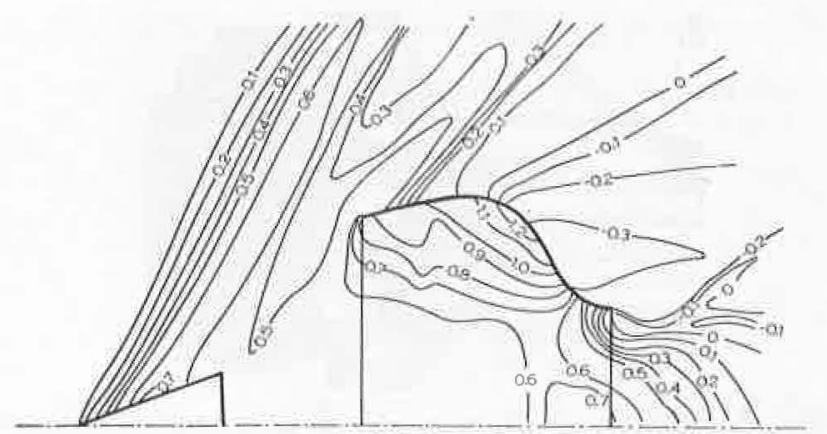

A) WITH OUTLET NOZZLE

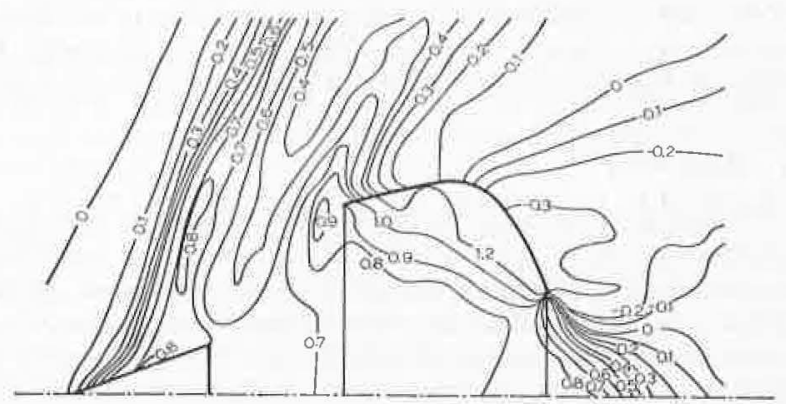

B) WITHOUT OUTLET NOZZLE

Fig. 14. Pressure distribution of two-dimensional parachute models with and without outlet nozzle at simulated Mach number 2.

projected parachute dismeter. Figure 15 shows such a flexible model in a supersonic wind tunnel, and Fig. 16 its schlieren picture. The schlieren picture shows the intricate shock-wave system originating at the forebody and at the parachute, as well as the effect of the wake of the forebody.

\section{Design Parameters}

Two essential points of the supersonic guide surface concept are the development of a steady and diverging wake and the prevention of air spillage. These points encompass a number of detailed considerations, a few of which will be discussed in the following sections.

\section{A. Diverging Wake}

The wake cone angle is essentially a function of Reynolds number, Mach number, and standoff distance. Since the mechanies of a turbulent and diverging wake is presently not susceptible to analytical treatment, the required information coneerning the wake angle was obtained from schlieren photographs and is summarized in Table $1 .{ }^{9}$ One observes a certain but mild dependency of the wake angle. Further investigations in this respect are desirable. However, this

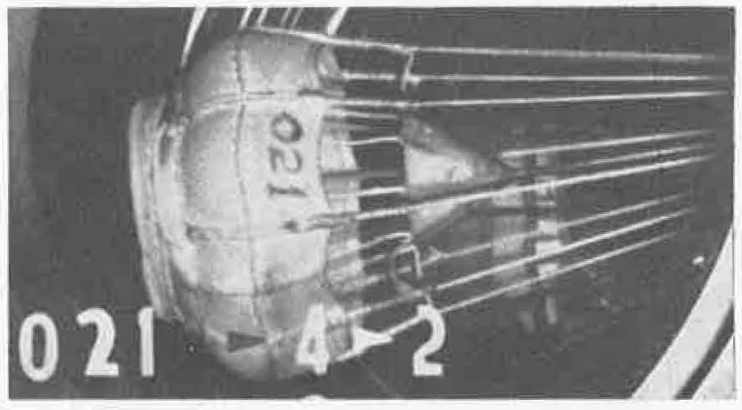

Fig. 15 Flexible model of the supersonic guide surface parachute with outlet nozzle at Mach number 2. 


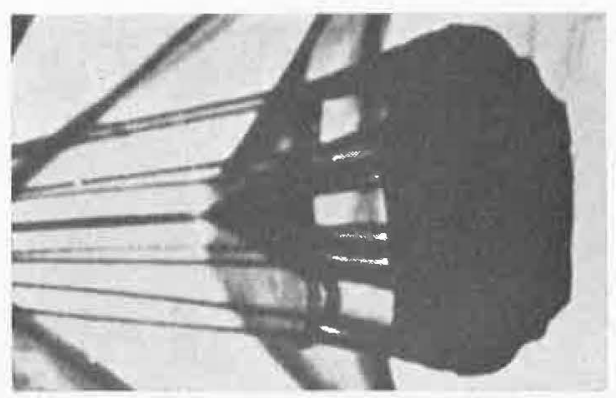

Fig. 16 Schlieren photograph of a flexible supersonic guide surface model at Mach number 3 behind a forebody.

study indicates that the aerodynamic conditions listed in Table 1 are suitable for the design of parachutes in the Mach number range from 0.9 to 4.5 . The range can probably be extended, but respective results are presently not available.

\section{B. Mass Flow}

For any given parachute problem the size of the parachute follows from the desired deceleration force. This condition determines the maximum diameter of the supersonic guide surface parachute. The concept of the parachute requires smooth mass flow, or, more specifically, the prevention of spillage. Therefore, the diameters of the cone and of the inlet and outlet, combined with the standoff distance, are the controlling parameters. Standoff distance and cone angle have been discussed previously. The diameter ratios are related to the mass-flow conditions and will be discussed below.

The theoretical mass flow, which can be absorbed without spillage, is contained in a stream tube that approaches from infinity, is deflected by the solid cone with its diverging wake, and intersects the rim of the canopy. For simplieity, it may be assumed that the apex angles of solid cone and diverged wake are equal. This scheme is shown in Fig. 17, and the characteristic stream tube can be calculated.

The actual mass flow at the exhaust area has been determined by means of pressure rakes, ${ }^{8,9}$ The ratio of measured to calculated mass flow $\dot{m} / \dot{m}_{\infty}$ then gives a good indication of the validity of the general assumptions. One observes in Fig. 17 that this ratio is very close to unity for Mach number 2, and for a certain range of standoff distance. The agreement between wind-tunnel and water analogy tests also is interesting.

Figure 17 also indicates some deviation of this mass-flow ratio from unity. However, considering that the stream tube is computed under the assumption that the wake diverges with the angle of the solid cone, and that turbulent mixture is neglected, the results are surprisingly good. Table 1 shows that the angle of the cone and wake are approximately equal merely for a few Mach and Reynolds numbers and for

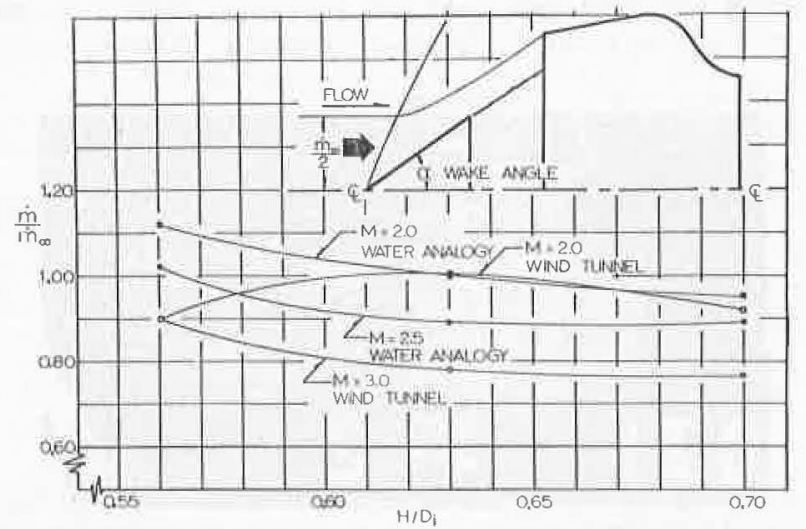

Fig. 17 Mass flow ratio vs standoff distance.

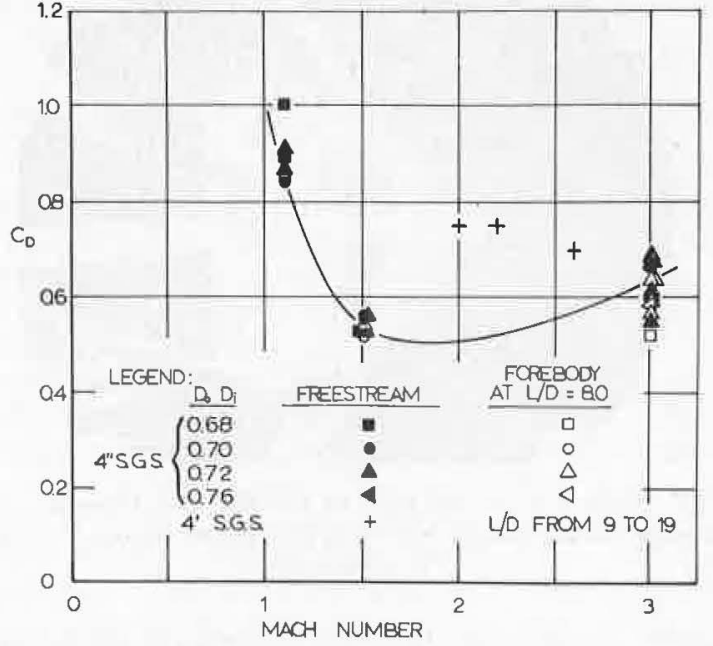

Fig. 18 Drag coefficient of flexible 4-in. models and of a 4-ft supersonic guide surface parachute.

certain standoff distances. When the divergence angle deviates from the cone angle, the actual stream tube differs from the computed one. Considering these facts, a review of the content of Table 1 and Fig. 17 actually gives a quantitative explanation of the deviation of the mass-flow ratio as shown in Fig. 17.

As in the preceding paragraph, the data presented in Fig. 17 are recommended for consideration in actual parachute design.

\section{Validation and Drag Coefficients}

Subsequent to the studies with small models, the U. S. Air Force tested a 4-ft supersonic guide surface parachute in a wind tunnel of the Arnold Engineering Development Center in Tullahoma, Tenn. ${ }^{10}$ All finished dimensions of this parachute were determined at the University of Minnesota on the basis of the data given previously. The parachute itself was built and assembled by a parachute manufacturer.

The 4-ft supersonic parachute functioned satisfactorily. It inflated properly, was aerodynamically stable and steady, and structurally as rigid as a parachute can be. Its appearance was essentially similar to the one of the 4-in. models. It finally was destroyed after being exposed to supersonic flow for about $90 \mathrm{~min}$. The cause of the failure could be traced to weak suspension-line connections caused by faulty manufacturing.

During the runs, there was ample time to determine the drag coefficients at several Mach numbers and various parachute positions behind the forebody. The drag coefficients are presented in Fig. 18, together with those of the 4-in. models. It can be seen that the drag coefficients of the

Table 1 Wake divergence angle behind a rigid cone of $68^{\circ}$ apex related to Mach number, Reynolds number, and standoff distance

\begin{tabular}{|c|c|c|c|c|}
\hline & $\mathrm{H}_{\mathrm{H} / \mathrm{D}_{i}} \mathrm{Re} / \mathrm{ft}$ & $2.08 \times 10^{6}$ & $1.88 \times 10^{6}$ & $5.58 \times 10^{5}$ \\
\hline \multirow{3}{*}{$\frac{T}{\frac{T}{U}} \frac{\pi}{\Sigma}$} & 0.56 & $\alpha=35.7^{\circ}$ & $\alpha=35.25^{\circ}$ & $\alpha=35^{\circ}$ \\
\hline & 0.63 & $\alpha=32^{\circ}$ & $\alpha=32.75^{\circ}$ & $\alpha=34.25$ \\
\hline & 0.70 & $\alpha=26^{\circ}$ & $\alpha=28^{\circ}$ & $\alpha=24.3^{\circ}$ \\
\hline \multirow{3}{*}{$\begin{array}{l}m \\
\frac{I}{U} \\
\frac{J}{\Sigma}\end{array}$} & 0.56 & $\alpha=40^{\circ}$ & & \\
\hline & 0.63 & $\alpha=35.5^{\circ}$ & & \\
\hline & 0.70 & $\alpha=29.8^{\circ}$ & & \\
\hline
\end{tabular}


4-ft parachute are somewhat higher than those of the small models. The higher drag coefficients may be caused by a difference in form which presently cannot be explained. Also, the projected diameter of the 4 -ft parachute was larger than expected. This may have been caused by the elasticity of the cloth and lines or through the rather loose line connections. The drag coefficients are in all cases based on the design diameter.

In spite of the differences of drag coefficients, the fact that the parachute that was 12 times larger, with a Reynolds number about 15 times as high, functioned essentially as the prototype models, may be taken as proof of the validity of the basic concept and of the value of experiments with small parachute models.

In summary, a 4-ft supersonic guide surface parachute, based on information obtained from model tests, has worked very well. However, the presented information should be considered merely as design guide lines. A parachute for supersonic application should undergo specific wind-tunnel tests under consideration of the operational conditions such as Mach number, Reynolds number, and forebody wake.

\section{References}

1 Meyer, R. A., "Wind tunnel investigation of conventional types of parachute canopies in supersonic flow," Wright Air Development Center Tech. Rept. 58-532 (1958).

"Connors, J. F. and Lovell, J. C., "Some observations on supersonic stabilization and deceleration devices," IAS Paper 60-19 (1960).

${ }^{3}$ Maynard, J. D., "Aerodynamic characteristics of parachutes at Mach numbers from 1.6 to 3.0," NASA Langley Researeh Center, Langley Field, Va., TN D-752 (1961).

"Heinrich, H. G., Rose, R. E., and Kovacevic, N. D., "Flow characteristics of rigid ribbon parachute eanopies in supersonic flow," Air Force Flight Development Lab. Tech. Rept. AFFDLTR-65-103 (1965).

"Engstrom, B. A., "Performance of trailing aerodynamic decelerators at high dynamic pressures," Wright Air Development Center Tech. Rept, 58-284, Pts. I-III (1960).

"Simms, L. W., "Evolution of the hyperflo parachute," Transactions of the Eighth Symposium on Ballistic Missile and Space Technology (Air Force Systems Command and Aerospace Corp., Los Angeles, Calif., 1963), Vol. II.

"Preiswerk, E., "Applieations of the methode of gas dynamies to water flows with free surfaces," NACA TN 934 and TN 935 (1940),

"Heinrich, H. G., "Acrodynamic characteristics of the supersonie guide surface parachute and the spiked ribbon parachutes;" Air Force Flight Development Lab. Tech. Rept. AFFDL-TR-65$104(1965)$.

${ }^{8}$ Bailey, R. O., "Analytical and experimental investigation of sensitivity to Mach number of the mass flow and flow field properties of the supersonic guide surface parachute," Master Thesis, Univ. of Minnesota, Minneapolis, Minn. (October 1963).

in Lowry, J. F., "Aerodynamic characteristics of various type of full seale prrachutes at Mach numbers from 1.8 to 3.0 , " Arnold Engineering Development, Center Tech. Rept. AEDC-TDR-64120 (1964). 
